\title{
A REVERSE LOGISTICS INVENTORY MODEL WITH MULTIPLE PRODUCTION AND REMANUFACTURING BATCHES UNDER FUZZY ENVIRONMENT
}

\author{
Swati Sharma ${ }^{1,2, *}$, Shiv Raj Singh² and Mohit Kumar ${ }^{3}$
}

\begin{abstract}
In the last few years, inventory modeling with reverse logistics has received more attention from both the academic world and industries. Most of the existing works in the literature believed that newly produced products and remanufactured products have the same quality. However, in many industries, customers do not consider remanufactured products as good as new ones. Therefore, this study develops a reverse logistics inventory model with multiple production and remanufacturing batches (cycles) under the fuzzy environment where the remanufactured products are of subordinate quality as compared to the newly produced products. As the precise estimation of inventory cost parameters such as holding cost, setup cost, etc. becomes often difficult; so these cost parameters are represented as triangular fuzzy numbers. Used products are purchased, screened and then suitable products are remanufactured. The production and remanufacturing rates are demand dependent. The main goal of this study is to obtain the optimal production and remanufacturing policy that minimizes the total cost per unit time of the proposed inventory system. The signed distance method is employed to defuzzify the total cost function. A numerical example is presented to demonstrate the developed model. Finally, sensitivity analysis is executed to study the impact of key parameters on the optimal solution.
\end{abstract}

Mathematics Subject Classification. 90B05.

Received June 26, 2017. Accepted February 12, 2021.

\section{INTRODUCTION}

Remanufacturing is an important issue for the manufacturers/suppliers due to the take back governmental and end users' expectations. In a world where re-use is considered environmentally friendly, product and material flows have changed all over the past decades. The reverse supply chain has been continually developed not only as a result of the associated economic profit but also because of the ecological interest. However, due to rapid development in technology and upcoming new industrial products, the number of unused products has increased. As a result, there has been significant growth in environmental problems in the global world. Due to the lawmaking regulations and consumer concerns for these environmental issues, a growing number of companies are

Keywords. Reverse logistics, production, remanufacturing, waste disposal, fuzzy number, signed distance method.

1 Central Institute of Petrochemicals Engineering \& Technology (CIPET): IPT, Ahmedabad 382445, Gujarat, India.

2 Department of Mathematics, Chaudhary Charan Singh University, Meerut 250004, Uttar Pradesh, India.

3 Department of Basic Sciences, Institute of Infrastructure, Technology, Research and Management, Ahmedabad 380026, Gujarat, India.

*Corresponding author: jmlashi0@gmail.com 
making efforts to reduce the amount of waste stream. Increasing ecological problems enforce companies to be more conservation liable. Hence, for the last few decades, there is a lot of curiosity for the reverse flow of products from consumers to upstream businesses. Firstly, Schrady [26] established an Economic Order Quantity (EOQ) model for repairable items, which allowed instantaneous production and repair rates with more than one repair cycle and one production cycle. Then, Nahmias and Rivera [21] extended Schrady's model by assuming a finite repair rate. Richter $[24,25]$ proposed an EOQ model with waste disposal and determined the optimal number of production and remanufacturing batches. Dobos and Richter [8] developed a production/recycling system with a single repair and a single production batch in a time interval. Later on, Dobos and Richter [9] generalized their earlier work by assuming multiple repair and production batches in a time period. Jaber and El Saadany [16] established an inventory model with the assumption that the remanufactured items are supposed to be of lower quality by the customers. El Saadany and Jaber [11] extended Dobos and Richter's earlier works by including price and quality dependant return rate. Alamri [1] presented a reverse logistics inventory model with variable production and demand by assuming adequate returned quantity as a decision variable. Hasanov et al. [14] extended the work of Jaber and El Saadany [16] with different cases of backordering. Further, Singh et al. [30] extended the work of Hasanov et al. [14] incorporating finite production and remanufacturing rates. Bazan et al. [2] presented an outstanding review of mathematical inventory models for reverse logistics. Polotski et al. [23] devised optimal production and setup policies for hybrid production-remanufacturing systems. Recently, Singh and Sharma [29] proposed a supply chain model under reverse logistics and inflation. Hasanov et al. [15] presented a four-level closed loop supply chain system with remanufacturing of the collected used products. Singh et al. [31] discussed a supplier-buyer reverse logistics model with variable production and remanufacturing under learning effects.

A look at the literature available on inventory reveals that several inventory models have been formulated in a static environment, where different inventory parameters are assumed to be known precisely. While, in some situations inventory parameters like production cost, setup cost, holding cost, etc. may be uncertain in an authentic world. To prevail over this obscurity, many practitioners and academicians made use of the fuzzy set theory. Zadeh [35] introduced the concept of fuzzy set theory. Fuzzy set theory has been applied in different areas such as inventory modeling, reliability engineering, decision-making problems and statistics [6,7,18-20,34]. Initially, Vujošević et al. [32] developed an EOQ formula by taking fuzzy inventory costs. Chang [5] discussed the fuzzy production inventory model for fuzzy production quantity. Yao et al. [34] proposed the fuzzy inventory model without backordering for fuzzy order quantity and fuzzy demand based on the triangular fuzzy numbers. Chang [4] developed an inventory model for defective items by using fuzzy set theory. Chen and Ouyang [6] established a fuzzy model with constant demand and proved that the total variable cost per unit time in the fuzzy sense was a strictly pseudo-convex function. Later, Halim et al. [13], Yadav et al. [33], Pal et al. [22], and Singh and Singh [27] provided some encouraging work in this direction with different assumptions. Then, Singh and Sharma [28] derived a production reliable model by assuming random demand and inflation. They maximized the expected profit of the inventory system in their model. Chen et al. [7] examined fuzzy multicycle manufacturing/remanufacturing decisions under the effect of inflation. Garai et al. [12] proposed a fuzzy inventory model with a price-sensitive demand rate and time varying inventory carrying cost.

The above survey reveals that very few researchers developed the models regarding remanufactured products not as good as new products, but they did not consider the fuzzy environment, purchasing, and screening costs for accumulated used products. Therefore, to make this study much closer to realistic situations we develop a reverse logistics inventory model in the fuzzy environment with demand dependent production and remanufacturing rates. The remanufactured products are not as good as the new products, consequently, the newly produced products sell in the primary market and remanufactured products sell in the secondary market at a reduced price $[3,16]$. Used products are purchased and screened at some costs and then appropriate products are remanufactured. Demand rates for the remanufactured and the newly produced products are different. We use an algebraic approach to develop and formulate the proposed model and implement the signed distance method to defuzzify the objective function. Moreover, a solution procedure is provided to achieve an optimal solution. The rest of this paper is structured as follows. Section 2 describes some preliminaries required to 
develop the proposed model. Section 3 presents the mathematical formulation of the model. Section 4 reports a numerical example. Section 5 presents a sensitivity analysis and provides some decision making observations. Finally, Section 6 provides the conclusion and further research directions.

\section{Preliminaries}

In this section, we describe all relevant definitions of fuzzy set theory for the development of proposed model $[4,10,17,36]$.

Definition 2.1. A fuzzy set $\tilde{A}$ on the universe of discourse $X$ can be defined as

$$
\tilde{A}=\left\{\left(x, \mu_{\tilde{A}}(x)\right): x \in X\right\},
$$

where $\mu_{\tilde{A}}(x)$ is the membership function which associates a real value in the interval $[0,1]$ to each element $x \in X$.

Definition 2.2. A fuzzy set $\tilde{A}$ on $R$ (real line) is called a fuzzy number if it satisfies the following conditions.

(i) $\tilde{A}$ is normal i.e. there exists $x_{0} \in R$ such that $\mu_{\tilde{A}}\left(x_{0}\right)=1$.

(ii) $\tilde{A}$ is fuzzy convex i.e. $\mu_{\tilde{A}}\left(\lambda x_{1}+\left(1-\lambda x_{2}\right)\right) \geq \min \left(\mu_{\tilde{A}}\left(x_{1}\right), \mu_{\tilde{A}}\left(x_{2}\right)\right)$ for every $x_{1}, x_{2} \in R, \lambda \in[0,1]$.

(iii) The support $S(\tilde{A})=\left\{x \in X: \mu_{\tilde{A}}(x)>0\right\}$ of $\tilde{A}$ is bounded.

In addition, let $\Omega$ be the family of all fuzzy numbers. A fuzzy number $\tilde{A}$ is called triangular fuzzy number (TFN) if its membership function $\mu_{\tilde{A}}$ is

$$
\mu_{\tilde{A}}(x)= \begin{cases}\frac{x-a}{b-a}, & \text { if } a \leq x<b \\ 1, & \text { if } x=b \\ \frac{c-x}{c-b}, & \text { if } b<x \leq c \\ 0, & \text { otherwise }\end{cases}
$$

where $a<b<c$. We denote TFN as $\tilde{A}=(a, b, c)$.

Definition 2.3. A fuzzy set $\tilde{c}_{\alpha}$ where $0 \leq \alpha \leq 1$ is called an $\alpha$-level fuzzy point at $c$ if its membership function on $R$ is

$$
\mu_{\tilde{c}_{\alpha}}(x)= \begin{cases}\alpha, & x=c \\ 0, & x \neq c\end{cases}
$$

Definition 2.4. A fuzzy set $\tilde{I}_{\alpha}[a, b]$, where $0 \leq \alpha \leq 1$ and defined on $R$, is called $\alpha$-level fuzzy interval if its membership function is

$$
\mu_{\tilde{I}_{\alpha}[a, b]}(x)= \begin{cases}\alpha, & a \leq x \leq b \\ 0, & \text { otherwise }\end{cases}
$$

Definition 2.5. The $\alpha$-cut of a fuzzy number $\tilde{A}$ is a crisp set $A_{\alpha}$ which is defined as

$$
\begin{aligned}
A_{\alpha} & =\left\{x \in R: \mu_{\tilde{A}}(x) \geq \alpha, 0 \leq \alpha \leq 1\right\} \\
& =\left[A_{L}(\alpha), A_{U}(\alpha)\right]
\end{aligned}
$$

where $A_{L}(\alpha)=\min \left\{x \in R: \mu_{\tilde{A}}(x) \geq \alpha\right\}$ is the left endpoint of the $\alpha$-cut and $A_{U}(\alpha)=\max \left\{x \in R: \mu_{\tilde{A}}(x) \geq \alpha\right\}$ is the right endpoint of the $\alpha$-cut. For TFN $\tilde{A}=(a, b, c)$, we obtain $A_{L}(\alpha)=a+(b-a) \alpha$ and $A_{U}(\alpha)=c-(c-b) \alpha$.

Definition 2.6. Let $r, 0 \in R$. The signed distance of $r$ from 0 is defined as $d_{0}(r, 0)=r$.

If $r>0$ then the signed distance between $r$ and 0 is $r=d_{0}(r, 0)$. Similarly, if $r<0$ then the signed distance between $r$ and 0 is $-r=-d_{0}(r, 0)$. Therefore, $d_{0}(r, 0)$ denotes the signed distance of $r$, which is measured from 0 . 
For any $\tilde{A} \in \Omega, A_{\alpha}=\left[A_{L}(\alpha), A_{U}(\alpha)\right]$, where both $A_{L}(\alpha)$ and $A_{U}(\alpha)$ are continuous functions for $0 \leq \alpha \leq 1$. We obtain the following result (see [4]).

$$
\tilde{A}=\bigcup_{0 \leq \alpha \leq 1} \tilde{I}_{\alpha}\left[A_{L}(\alpha), A_{U}(\alpha)\right]
$$

From signed distance definition, we find that the signed distance of left end point and right end point of the $\alpha$-cut $A_{\alpha}$ from the origin 0 is $d_{0}\left(A_{L}(\alpha), 0\right)=A_{L}(\alpha)$ and $d_{0}\left(A_{U}(\alpha), 0\right)=A_{U}(\alpha)$, respectively. Therefore, the signed distance of the $\alpha$-cut interval $A_{\alpha}=\left[A_{L}(\alpha), A_{U}(\alpha)\right]$ from the origin 0 is defined as

$$
d_{0}\left(\left[A_{L}(\alpha), A_{U}(\alpha)\right], 0\right)=\frac{1}{2}\left[d_{0}\left(A_{L}(\alpha), 0\right)+d_{0}\left(A_{U}(\alpha), 0\right)\right]=\frac{1}{2}\left[A_{L}(\alpha)+A_{U}(\alpha)\right] .
$$

In addition, for each $0 \leq \alpha \leq 1$, there is a one-to-one mapping between the $\alpha$-level fuzzy interval $\tilde{I}_{\alpha}\left[A_{L}(\alpha), A_{U}(\alpha)\right]$ and the real interval $\left[A_{L}(\alpha), A_{U}(\alpha)\right]$ i.e.,

$$
\tilde{I}_{\alpha}\left[A_{L}(\alpha), A_{U}(\alpha)\right] \leftrightarrow\left[A_{L}(\alpha), A_{U}(\alpha)\right]
$$

Moreover, the 1-level fuzzy point $\tilde{0}_{1}$ is mapping to the real number 0 . Hence, the signed distance of $\tilde{I}_{\alpha}\left[A_{L}(\alpha), A_{U}(\alpha)\right]$ which is measured from $\tilde{0}_{1}$ can be defined as

$$
d\left(\tilde{I}_{\alpha}\left[A_{L}(\alpha), A_{U}(\alpha)\right], \tilde{0}_{1}\right)=d_{0}\left(\left[A_{L}(\alpha), A_{U}(\alpha)\right], 0\right)=\frac{1}{2}\left[A_{L}(\alpha)+A_{U}(\alpha)\right] .
$$

Since the above function is continuous on $0 \leq \alpha \leq 1$, we can use the integration method to obtain the mean value of the signed distance as follows:

$$
\int_{0}^{1} d\left(\tilde{I}_{\alpha}\left[A_{L}(\alpha), A_{U}(\alpha)\right], \tilde{0}_{1}\right) \mathrm{d} \alpha=\frac{1}{2} \int_{0}^{1}\left[A_{L}(\alpha)+A_{U}(\alpha)\right] \mathrm{d} \alpha .
$$

Now, from (2.6) and (2.10) we have the following definition.

Definition 2.7. For $\tilde{A} \in \Omega$, the signed distance of $\tilde{A}$ from $\tilde{0}_{1}$ is defined as follows:

$$
d\left(\tilde{A}, \tilde{0}_{1}\right)=\int_{0}^{1} d\left(\tilde{I}_{\alpha}\left[A_{L}(\alpha), A_{U}(\alpha)\right], \tilde{0}_{1}\right) \mathrm{d} \alpha=\frac{1}{2} \int_{0}^{1}\left[A_{L}(\alpha)+A_{U}(\alpha)\right] \mathrm{d} \alpha .
$$

The most important properties, based on the above definition and results are given as follows:

Property 1. Consider the TFN $\tilde{A}=(a, b, c)$, with $\alpha$-cut $A_{\alpha}=\left[A_{L}(\alpha), A_{U}(\alpha)\right], 0 \leq \alpha \leq 1$ where $A_{L}(\alpha)=$ $a+(b-a) \alpha$ and $A_{U}(\alpha)=c-(c-b) \alpha$. Then the signed distance of $\tilde{A}$ measured from $\tilde{0}_{1}$ is defined as

$$
d\left(\tilde{A}, \tilde{0}_{1}\right)=\frac{1}{2} \int_{0}^{1}\left[A_{L}(\alpha)+A_{U}(\alpha)\right] \mathrm{d} \alpha=\frac{1}{4}(a+2 b+c) .
$$

Property 2. Consider $\tilde{A}, \tilde{B} \in \Omega$ and $k \in R$,

$$
\begin{aligned}
& \text { (i) } d\left(\tilde{A} \oplus \tilde{B}, \tilde{0}_{1}\right)=d\left(\tilde{A}, \tilde{0}_{1}\right)+d\left(\tilde{B}, \tilde{0}_{1}\right) . \\
& \text { (ii) } d\left(\tilde{A} \Theta \tilde{B}, \tilde{0}_{1}\right)=d\left(\tilde{A}, \tilde{0}_{1}\right)-d\left(\tilde{B}, \tilde{0}_{1}\right) . \\
& \text { (iii) } d\left(k \tilde{A}, \tilde{0}_{1}\right)=k d\left(\tilde{A}, \tilde{0}_{1}\right) .
\end{aligned}
$$

\section{Mathematical Formulation of the Proposed MOdel}

This section presents the mathematical formulation of the proposed model under crisp and fuzzy environments. The following notations and assumptions are utilized throughout this study. 


\subsection{Notations and assumptions}

The following notations are used in the formulation of the proposed model:

$D_{p} \quad$ Demand rate for newly produced products (units/unit of time).

$D_{r} \quad$ Demand rate for remanufactured products (units/unit of time), where $D_{r}$ is not necessarily equal to $D_{p}$.

$D_{p} / \eta \quad$ Production rate $(0<\eta<1)$.

$D_{r} / \delta \quad$ Remanufacturing rate $(0<\delta<1)$.

$\beta_{p} \quad$ Proportion of returns collected (purchased) from the primary market of produced products.

$\beta_{r} \quad$ Proportion of returns collected (purchased) from the secondary market of remanufactured products $\left(0<\beta_{r} \leq \beta_{p}<1\right)$.

$S_{p} \quad$ Setup cost for a production cycle $(\$)$.

$S_{r} \quad$ Setup cost for a remanufacturing cycle $(\$)$.

$h_{p} \quad$ Holding cost per unit per unit of time of a newly produced product (\$/unit/unit of time).

$h_{r} \quad$ Holding cost per unit per unit of time of a remanufactured product (\$/unit/unit of time).

$h_{R} \quad$ Holding cost per unit per unit of time of a used product (\$/unit/unit of time).

$c_{p} \quad$ Per unit production cost $(\$ /$ unit).

$c_{r} \quad$ Per unit remanufacturing cost $(\$ /$ unit).

$c_{w} \quad$ Per unit disposal cost of unrecoverable used product (\$/unit).

$c_{s} \quad$ Per unit screening cost of accumulated used product (\$/unit).

$c_{R} \quad$ Per unit buyback (or purchasing) cost of used product (\$/unit).

$T_{R} \quad$ Length of a remanufacturing cycle (units of time).

$T_{P} \quad$ Length of a production cycle (units of time).

$T \quad$ Length of the time interval (units of time).

$m \quad$ Number of remanufacturing cycles in an interval of length $T$ (a decision variable).

$n \quad$ Number of production cycles in an interval of length $T$ (a decision variable).

$\gamma_{r} \quad$ Remanufacturable proportion of collected returns from the secondary market of remanufactured products, $0 \leq \gamma_{r} \leq 1$, (a decision variable).

$\gamma_{p} \quad$ Remanufacturable proportion of collected returns from the primary market of newly produced products, $\gamma_{\min }<\gamma_{p} \leq 1$, (a decision variable); where $\gamma_{\min }=0.01$ (Jaber and El Saadany [16], pp. $120)$.

The following assumptions are made to ensure the ease of the developed model:

(1) Production and remanufacturing rates are finite and dependent on demand rates. This assumption implies that the production rate depends on the demand rate for the newly produced products and the remanufacturing rate depends on the demand rate for the remanufactured products $[8,11,30]$.

(2) A single product case is taken with two dissimilar qualities [14,16,30] and shortages are not allowed.

(3) In practices, some customers recognize remanufactured products to be of subordinate quality than newly produced products. Therefore, it is assumed that remanufactured products are not as good as newly produced $[16,30]$.

(4) Demand rates for newly produced and remanufactured products are well-known, constant but dissimilar $[16,30]$. This assumption is convenient because there is a quality difference between the newly produced and the remanufactured products and sell in the different markets.

(5) Used products (returns) are purchased $[9,11,29,31]$ and screened at some costs.

(6) The planning horizon is infinite.

(7) Collection rates for used newly produced and remanufactured products are constant but dissimilar $[16,30]$.

\subsection{Crisp reverse logistics inventory model}

This subsection develops a production and remanufacturing model with reverse logistics in the crisp environment. Similar to that of Richter [25], the production and remanufacturing system illustrated in Figure 1 consists of two stores. First store (serviceable stock), produces new products and remanufactures used products collected 


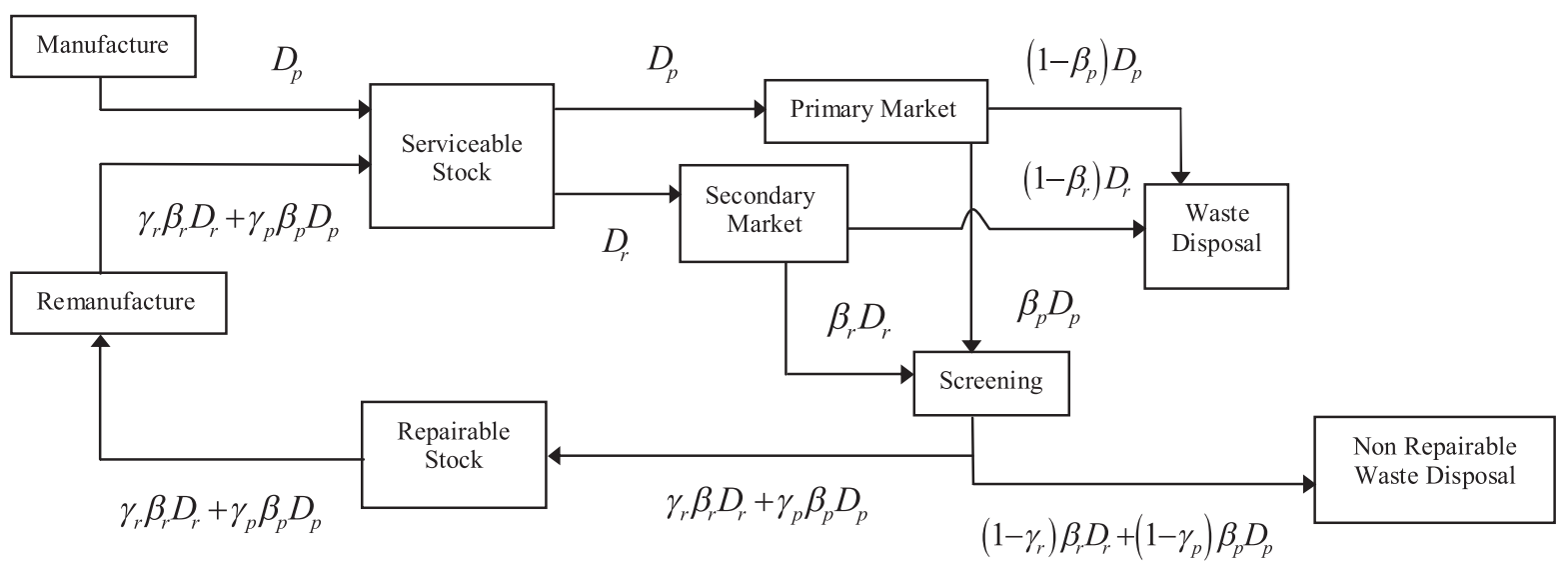

FiguRE 1. Material flow for a production and remanufacturing system.

by the second store (repairable stock). The remanufactured products are of secondary quality as compared to the new ones. So, newly produced products sell in the primary market even as remanufactured products sell in the secondary market at a reduced price. Collect the used products from the primary and the secondary markets and then the screening process takes place at a fixed cost. Dispose of the non-repairable products outside the system at some cost and remanufacture the repairable products. Demand is fulfilled from newly produced and remanufactured products accordingly as shown in Figure 1. There are $m$ remanufacturing cycles each of length $T_{R}$ and $n$ production cycles each of length $T_{P}$ over the time interval $T$. Demand for the remanufactured/newly produced products is not admitted during the production/remanufacturing cycles. Repairable used products are assembled at the rates $\gamma_{r} \beta_{r} D_{r}$ and $\gamma_{p} \beta_{p} D_{p}$ over the period $m T_{R}$ and $n T_{P}$ respectively.

The model begins with the remanufacturing process (using the repairable used products stored in the former production and remanufacturing cycles). During the remanufacturing cycle inventory level of the remanufactured products augments initially due to the joint cause of the remanufacturing and demand rate of the remanufactured products. It continues up to the time point $\delta T_{R}$, where remanufacturing ceases. After that, inventory level starts depleting due to the demand rate only and reduces completely at time $T_{R}$. Thus, all $m$ remanufacturing cycles of equal length $T_{R}$ take place. Then, production cycles start occurring. At initial phase of a production cycle inventory level builds due to the joint effect of the production and demand rate of the newly produced products. It continues up to the time point $\eta T_{P}$, where production process ceases. Then, inventory level starts depleting due to the demand rate only and reduces completely at time $T_{P}$. Thus, all $n$ production cycles of equal length $T_{P}$ take place. Such an inventory system for $m=2$ and $n=3$ is depicted in Figure 2.

Initially, when remanufacturing starts the inventory level of repairable stock (used products) depletes due to the combined effect of accumulation of repairable stock and remanufacturing. After that, inventory level builds up owing to the accumulation of the repairable stock. Same process of depletion/builds up of the inventory level takes place for all $m$ remanufacturing cycles. After that, during $n$ production cycles inventory level of the repairable stock enlarges due to the accumulation of the used products and achieves its maximum height at time point $T$ (as shown in Fig. 2).

The total cost per unit time for the proposed reverse logistics inventory system $\left(C\left(m, n, \gamma_{r}, \gamma_{p}, T\right)\right)$ is the sum of the setup cost per unit time for the system, the total inventory holding cost per unit time, the disposal cost per unit time for the system, the remanufacturing cost per unit time, the production cost per unit time, the purchasing cost per unit time for used products and the screening cost per unit time for used products and 
Serviceable Stock

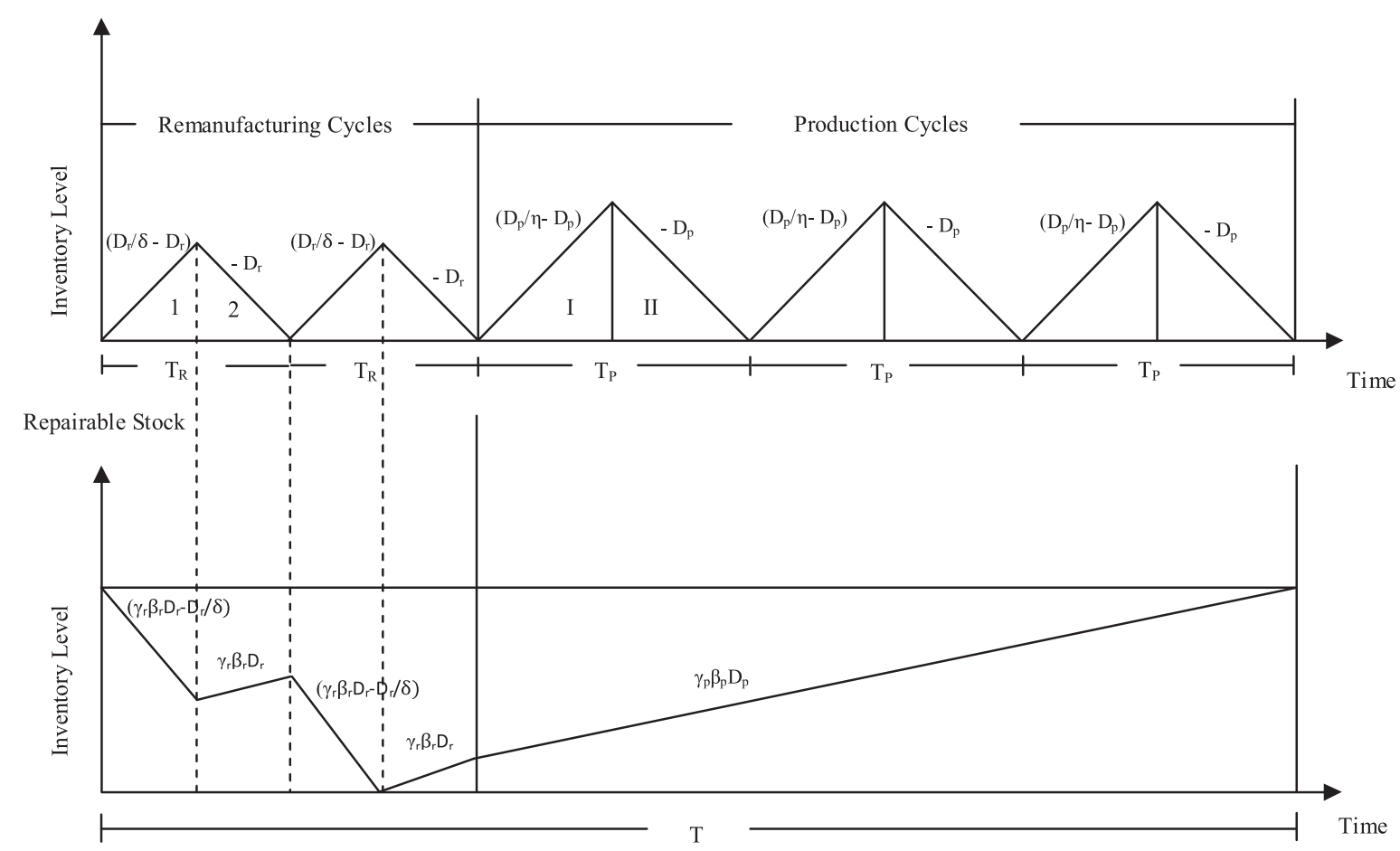

FIGURE 2. Inventory system for $m=2, n=3$.

is given as

$$
\begin{aligned}
C\left(m, n, \gamma_{r}, \gamma_{p}, T\right)= & {\left[\frac{\left(m S_{r}+n S_{p}\right)}{T}+T \phi\left(m, n, \gamma_{r}, \gamma_{p}\right)+\frac{D_{r} D_{p}}{g}\left\{c_{w} \beta_{p}\left(1-\gamma_{p}+\beta_{r}\left(\gamma_{p}-\gamma_{r}\right)\right)\right.\right.} \\
& \left.\left.+c_{r} \gamma_{p} \beta_{p}+c_{p}\left(1-\gamma_{r} \beta_{r}\right)+\left(c_{R}+c_{s}\right) \beta_{p}\left(1-\gamma_{r} \beta_{r}+\gamma_{p} \beta_{r}\right)\right\}\right] .
\end{aligned}
$$

(See Appendices A-C for details.)

Equation (3.1) is convex over $T$ as $\partial^{2} C\left(m, n, \gamma_{r}, \gamma_{p}, T\right) / \partial T^{2}=2\left(m S_{r}+n S_{p}\right) / T^{3}>0, \forall T>0$. Now, putting the first order partial derivative of equation (3.1) equal to zero and solving for $T$, we get

$$
T=\sqrt{\left(m S_{r}+n S_{p}\right) / \phi\left(m, n, \gamma_{r}, \gamma_{p}\right)} .
$$

Substituting the value of $T$ from equation (3.2) in (3.1), equation (3.1) reduces to

$$
\begin{aligned}
C\left(m, n, \gamma_{r}, \gamma_{p}\right)= & {\left[2 \sqrt{\left(m S_{r}+n S_{p}\right) \phi\left(m, n, \gamma_{r}, \gamma_{p}\right)}+\frac{D_{r} D_{p}}{g}\left\{c_{w} \beta_{p}\left(1-\gamma_{p}+\beta_{r}\left(\gamma_{p}-\gamma_{r}\right)\right)\right.\right.} \\
& \left.\left.+c_{r} \gamma_{p} \beta_{p}+c_{p}\left(1-\gamma_{r} \beta_{r}\right)+\left(c_{s}+c_{R}\right) \beta_{p}\left(1-\gamma_{r} \beta_{r}+\gamma_{p} \beta_{r}\right)\right\}\right] .
\end{aligned}
$$

\subsection{Fuzzy reverse logistics inventory model}

In this subsection, we develop fuzzy model subsequent to the crisp model developed above. 
Let us consider cost parameters $h_{p}, h_{r}, h_{R}, S_{r}, S_{p}, c_{w}, c_{r}, c_{p}, c_{s}$ and $c_{R}$ are imprecise and expressed by triangular fuzzy numbers such as $\tilde{h}_{p}, \tilde{h}_{r}, \hat{h}_{R}, \tilde{S}_{r}, \tilde{S}_{p}, \tilde{c}_{w}, \tilde{c}_{r}, \tilde{c}_{p}, \tilde{c}_{s}$ and $\tilde{c}_{R}$, respectively and given by

$$
\begin{aligned}
\tilde{S}_{r} & =\left(S_{r}-\Delta_{11}, S_{r}, S_{r}+\Delta_{12}\right), \\
\tilde{S}_{p} & =\left(S_{p}-\Delta_{21}, S_{p}, S_{p}+\Delta_{22}\right), \\
\tilde{h}_{p} & =\left(h_{p}-\Delta_{31}, h_{p}, h_{p}+\Delta_{32}\right), \\
\tilde{h}_{r} & =\left(h_{r}-\Delta_{41}, h_{r}, h_{r}+\Delta_{42}\right), \\
\tilde{h}_{R} & =\left(h_{R}-\Delta_{51}, h_{R}, h_{R}+\Delta_{52}\right), \\
\tilde{c}_{w} & =\left(c_{w}-\Delta_{61}, c_{w}, c_{w}+\Delta_{62}\right), \\
\tilde{c}_{r} & =\left(c_{r}-\Delta_{71}, c_{r}, c_{r}+\Delta_{72}\right), \\
\tilde{c}_{p} & =\left(c_{p}-\Delta_{81}, c_{p}, c_{p}+\Delta_{82}\right), \\
\tilde{c}_{s} & =\left(c_{s}-\Delta_{91}, c_{s}, c_{s}+\Delta_{92}\right), \\
\tilde{c}_{R} & =\left(c_{R}-\Delta_{101}, c_{R}, c_{R}+\Delta_{102}\right),
\end{aligned}
$$

where $0<\Delta_{11}<S_{r}$ and $\Delta_{12}>0$

where $0<\Delta_{21}<S_{p}$ and $\Delta_{22}>0$

where $0<\Delta_{31}<h_{p}$ and $\Delta_{32}>0$

where $0<\Delta_{41}<h_{r}$ and $\Delta_{42}>0$

where $0<\Delta_{51}<h_{R}$ and $\Delta_{52}>0$

where $0<\Delta_{61}<c_{w}$ and $\Delta_{62}>0$

where $0<\Delta_{71}<c_{r}$ and $\Delta_{72}>0$

where $0<\Delta_{81}<c_{p}$ and $\Delta_{82}>0$

where $0<\Delta_{91}<c_{s}$ and $\Delta_{92}>0$

where $0<\Delta_{101}<c_{R}$ and $\Delta_{102}>0$.

Here $\Delta_{i 1}$ and $\Delta_{i 2}$, where $i=1,2,3, \ldots, 10$ are decided by the decision-makers. Thus, the total cost per unit of time in fuzzy sense is

$$
\begin{aligned}
\tilde{C} \equiv & \tilde{C}\left(m, n, \gamma_{r}, \gamma_{p}, T\right)=\left[\frac{\left(m \tilde{S}_{r}+n \tilde{S}_{p}\right)}{T}+T \tilde{\phi}\left(m, n, \gamma_{r}, \gamma_{p}\right)+\frac{D_{r} D_{p}}{g}\left\{\tilde{c}_{w} \beta_{p}\left(1-\gamma_{p}+\beta_{r}\left(\gamma_{p}-\gamma_{r}\right)\right)\right.\right. \\
& \left.\left.+\tilde{c}_{r} \gamma_{p} \beta_{p}+\tilde{c}_{p}\left(1-\gamma_{r} \beta_{r}\right)+\left(\tilde{c}_{s}+\tilde{c}_{R}\right) \beta_{p}\left(1-\gamma_{r} \beta_{r}+\gamma_{p} \beta_{r}\right)\right\}\right]
\end{aligned}
$$

where, $g=D_{r}+\gamma_{\mathrm{p}} \beta_{\mathrm{p}} D_{p}-\gamma_{\mathrm{r}} \beta_{\mathrm{r}} D_{\mathrm{r}}$ and $\tilde{\phi}\left(m, n, \gamma_{r}, \gamma_{p}\right)$ is as follows:

$$
\begin{aligned}
\tilde{\phi}\left(m, n, \gamma_{r}, \gamma_{p}\right)= & \frac{D_{r} D_{p}}{2 g^{2}}\left[\frac{\tilde{h}_{p}(1-\eta)\left(1-\gamma_{r} \beta_{r}\right)^{2} D_{r}}{n}+\frac{\tilde{h}_{r}(1-\delta) \gamma_{p}^{2} \beta_{p}^{2} D_{p}}{m}\right. \\
& +\frac{\tilde{h}_{R} \gamma_{p}^{2} \beta_{p}^{2} D_{p}}{m}\left\{\left(1-\delta \gamma_{r} \beta_{r}\right) \delta+\gamma_{r} \beta_{r}(1-\delta)^{2}+\frac{m\left(1-\gamma_{r} \beta_{r}\right)^{2} D_{r}}{\gamma_{p} \beta_{p} D_{p}}\right. \\
& \left.\left.+\left(1-\gamma_{r} \beta_{r}\right)(m-1)+\frac{2 \gamma_{r} \beta_{r} D_{r}(1-\delta)\left(1-\gamma_{r} \beta_{r}\right)}{\gamma_{p} \beta_{p} D_{p}}\right\}\right]
\end{aligned}
$$

Now, we defuzzify $\tilde{C}\left(m, n, \gamma_{r}, \gamma_{p}, T\right)$ using the signed distance method. From Property 2, the signed distance of $\tilde{C}\left(m, n, \gamma_{r}, \gamma_{p}, T\right)$ to $\tilde{0}_{1}$ is

$$
\begin{aligned}
d\left(\tilde{C}, \tilde{0}_{1}\right)= & {\left[\frac{m}{T} d\left(\tilde{S}_{r}, \tilde{0}_{1}\right)+\frac{n}{T} d\left(\tilde{S}_{p}, \tilde{0}_{1}\right)+T d\left(\tilde{\phi}\left(m, n, \gamma_{r}, \gamma_{p}\right), \tilde{0}_{1}\right)\right.} \\
& +\frac{D_{r} D_{p}}{g}\left\{\beta_{p}\left(1-\gamma_{p}+\beta_{r}\left(\gamma_{p}-\gamma_{r}\right)\right) \times d\left(\tilde{c}_{w}, \tilde{0}_{1}\right)+\gamma_{p} \beta_{p} d\left(\tilde{c}_{r}, \tilde{0}_{1}\right)\right. \\
& \left.\left.+\left(1-\gamma_{r} \beta_{r}\right) d\left(\tilde{c}_{p}, \tilde{0}_{1}\right)+\beta_{p}\left(1-\gamma_{r} \beta_{r}+\gamma_{p} \beta_{r}\right)\left(d\left(\tilde{c}_{s}, \tilde{0}_{1}\right)+d\left(\tilde{c}_{R}, \tilde{0}_{1}\right)\right)\right\}\right] .
\end{aligned}
$$

From Property 1 , the signed distance of fuzzy number $\tilde{S}_{r}$ to $\tilde{0}_{1}$ is

$$
\left.d\left(\tilde{S}_{r}, \tilde{0}_{1}\right)=\frac{1}{4}\left[S_{r}-\Delta_{11}\right]+2 S_{r}+\left(S_{r}+\Delta_{12}\right)\right]=S_{r}+\frac{\left(\Delta_{12}-\Delta_{11}\right)}{4} .
$$


Similarly, we can write the signed distance for other fuzzy cost parameters.

Therefore, the defuzzified total cost per unit time becomes

$$
\begin{aligned}
Z\left(m, n, \gamma_{r}, \gamma_{p}, T\right)= & d\left(\tilde{C}, \tilde{0}_{1}\right)=\left[\frac{m}{T}\left(S_{r}+\frac{\left(\Delta_{12}-\Delta_{11}\right)}{4}\right)+\frac{n}{T}\left(S_{p}+\frac{\left(\Delta_{22}-\Delta_{21}\right)}{4}\right)\right. \\
& +T \xi\left(m, n, \gamma_{r}, \gamma_{p}\right)+\frac{D_{r} D_{p}}{g}\left\{\beta_{p}\left(1-\gamma_{p}+\beta_{r}\left(\gamma_{p}-\gamma_{r}\right)\right)\right. \\
& \times\left(c_{w}+\frac{\left(\Delta_{62}-\Delta_{61}\right)}{4}\right)+\gamma_{p} \beta_{p}\left(c_{r}+\frac{\left(\Delta_{72}-\Delta_{71}\right)}{4}\right)+\left(1-\gamma_{r} \beta_{r}\right) \\
& \times\left(c_{p}+\frac{\left(\Delta_{82}-\Delta_{81}\right)}{4}\right)+\beta_{p}\left(1-\gamma_{r} \beta_{r}+\gamma_{p} \beta_{r}\right)\left(\left(c_{s}+\frac{\left(\Delta_{92}-\Delta_{91}\right)}{4}\right)\right. \\
& \left.\left.\left.+\left(c_{R}+\frac{\left(\Delta_{102}-\Delta_{101}\right)}{4}\right)\right)\right\}\right]
\end{aligned}
$$

where

$$
\begin{aligned}
\xi\left(m, n, \gamma_{r}, \gamma_{p}\right)= & d\left(\tilde{\phi}\left(m, n, \gamma_{r}, \gamma_{p}\right), \tilde{0}_{1}\right) \\
= & \frac{D_{r} D_{p}}{2 g^{2}}\left[\frac{(1-\eta)\left(1-\gamma_{r} \beta_{r}\right)^{2} D_{r}}{n}\left(h_{p}+\frac{\left(\Delta_{32}-\Delta_{31}\right)}{4}\right)\right. \\
& +\frac{(1-\delta) \gamma_{p}^{2} \beta_{p}^{2} D_{p}}{m}\left(h_{r}+\frac{\left(\Delta_{42}-\Delta_{41}\right)}{4}\right)+\frac{m\left(1-\gamma_{r} \beta_{r}\right)^{2} D_{r}}{\gamma_{p} \beta_{p} D_{p}} \\
& +\frac{\gamma_{p}^{2} \beta_{p}^{2} D_{p}}{m}\left\{\left(1-\delta \gamma_{r} \beta_{r}\right) \delta+\gamma_{r} \beta_{r}(1-\delta)^{2}+\left(1-\gamma_{r} \beta_{r}\right)(m-1)\right. \\
& \left.\left.+\frac{2 \gamma_{r} \beta_{r} D_{r}(1-\delta)\left(1-\gamma_{r} \beta_{r}\right)}{\gamma_{p} \beta_{p} D_{p}}\right\}\left(h_{R}+\frac{\left(\Delta_{52}-\Delta_{51}\right)}{4}\right)\right] .
\end{aligned}
$$

Now, equation (3.8) is convex over $T$, as $\frac{\partial^{2} Z\left(m, n, \gamma_{r}, \gamma_{p}, T\right)}{\partial T^{2}}=\frac{2}{T^{3}}\left[m\left(S_{r}+\frac{\left(\Delta_{12}-\Delta_{11}\right)}{4}\right)+n\left(S_{p}+\frac{\left(\Delta_{22}-\Delta_{21}\right)}{4}\right)\right]>$ $0, \forall T>0$. Now, putting the first order partial derivative of equation (3.8) equal to zero and solving for $T$, we get

$$
T=\sqrt{\frac{m\left(S_{r}+\frac{\left(\Delta_{12}-\Delta_{11}\right)}{4}\right)+n\left(S_{p}+\frac{\left(\Delta_{22}-\Delta_{21}\right)}{4}\right)}{\xi\left(m, n, \gamma_{r}, \gamma_{p}\right)}} .
$$

Substituting the value of $T$ from equation (3.10) in (3.8), equation (3.8) reduces to

$$
\begin{aligned}
Z\left(m, n, \gamma_{r}, \gamma_{p}\right)= & {\left[2 \sqrt{\left[m\left(S_{r}+\frac{\left(\Delta_{12}-\Delta_{11}\right)}{4}\right)+n\left(S_{p}+\frac{\left(\Delta_{22}-\Delta_{21}\right)}{4}\right)\right] \xi\left(m, n, \gamma_{r}, \gamma_{p}\right)}\right.} \\
& +\frac{D_{r} D_{p}}{g}\left\{\beta_{p}\left(1-\gamma_{p}+\beta_{r}\left(\gamma_{p}-\gamma_{r}\right)\right)\left(c_{w}+\frac{\left(\Delta_{62}-\Delta_{61}\right)}{4}\right)\right. \\
& +\gamma_{p} \beta_{p}\left(c_{r}+\frac{\left(\Delta_{72}-\Delta_{71}\right)}{4}\right)+\left(1-\gamma_{r} \beta_{r}\right)\left(c_{p}+\frac{\left(\Delta_{82}-\Delta_{81}\right)}{4}\right) \\
& \left.\left.+\beta_{p}\left(1-\gamma_{r} \beta_{r}+\gamma_{p} \beta_{r}\right)\left(\left(c_{s}+\frac{\left(\Delta_{92}-\Delta_{91}\right)}{4}\right)+\left(c_{R}+\frac{\left(\Delta_{102}-\Delta_{101}\right)}{4}\right)\right)\right\}\right] .
\end{aligned}
$$

The following solution procedure is employed to obtain the optimal production and remanufacturing policy that minimizes the total cost per unit time given in equation (3.11). 
TABLE 1 . The computational results with different $m$ and $n$ values.

\begin{tabular}{llllllll}
\hline \hline Trial & $m$ & $n$ & $\gamma_{r}$ & $\gamma_{p}$ & $Q_{r}$ & $Q_{p}$ & $Z\left(m, n, \gamma_{r}, \gamma_{p}\right)$ \\
\hline 1 & 1 & 1 & 0.571150 & 0.713450 & 495.408 & 471.382 & 6087.15 \\
2 & 2 & 1 & 1.000000 & 0.604064 & 945.920 & 391.482 & 5957.26 \\
3 & $3^{*}$ & $1^{*}$ & $1.000000^{*}$ & $0.904767^{*}$ & $1316.570^{*}$ & $363.787^{*}$ & $5934.89^{*}$ \\
4 & 4 & 1 & 1.000000 & 1.000000 & 1606.520 & 401.630 & 5953.98 \\
5 & 1 & 2 & 0.554470 & 0.188116 & 331.448 & 972.155 & 6279.27 \\
6 & 2 & 2 & 1.000000 & 0.218705 & 871.257 & 995.927 & 6183.64 \\
7 & 3 & 2 & 1.000000 & 0.354274 & 1280.450 & 903.575 & 6142.91 \\
8 & 4 & 2 & 1.000000 & 0.473434 & 1625.120 & 858.155 & 6139.19 \\
9 & 5 & 2 & 1.000000 & 0.577354 & 1929.070 & 835.308 & 6156.00 \\
\hline
\end{tabular}

Notes. ${ }^{*}$ Represents the optimal solution.

\subsection{Solution procedure}

Input the parameters $D_{r}, D_{p}, S_{p}, S_{r}, h_{p}, h_{r}, h_{R}, \beta_{p}, \beta_{r}, c_{w}, c_{p}, c_{r}, c_{s}, c_{R}, \delta, \eta, \Delta_{11}, \Delta_{12}, \Delta_{21}, \Delta_{22}, \Delta_{31}$, $\Delta_{32}, \Delta_{41}, \Delta_{42}, \Delta_{51}, \Delta_{52}, \Delta_{61}, \Delta_{62}, \Delta_{71}, \Delta_{72}, \Delta_{81}, \Delta_{82}, \Delta_{91}, \Delta_{92}, \Delta_{101}, \Delta_{102}$ and then proceed as follows.

Step 1. Set $n=1, m=1$ and optimize $Z\left(1,1, \gamma_{r}, \gamma_{p}\right)$. Record the values of $Z\left(1,1, \gamma_{r}, \gamma_{p}\right), \gamma_{r(1,1)}^{*}$ and $\gamma_{p(1,1)}^{*}$.

Step 2. Repeat Step 1 for $m=2, n=1$ and record $Z\left(2,1, \gamma_{r}, \gamma_{p}\right), \gamma_{r(2,1)}^{*}$ and $\gamma_{p(2,1)}^{*}$. Compare $Z\left(1,1, \gamma_{r}, \gamma_{p}\right)$ and $Z\left(2,1, \gamma_{r}, \gamma_{p}\right)$. If $Z\left(1,1, \gamma_{r}, \gamma_{p}\right)<Z\left(2,1, \gamma_{r}, \gamma_{p}\right)$, terminate the search for $n=1$ and record the value of $Z\left(1,1, \gamma_{r}, \gamma_{p}\right)$. If $Z\left(1,1, \gamma_{r}, \gamma_{p}\right)>Z\left(2,1, \gamma_{r}, \gamma_{p}\right)$, repeat step 1 for $m=3, m=4$, etc. Terminate once $Z\left(m_{1}^{*}-1,1, \gamma_{r}, \gamma_{p}\right)>Z\left(m_{1}^{*}, 1, \gamma_{r}, \gamma_{p}\right)<Z\left(m_{1}^{*}+1,1, \gamma_{r}, \gamma_{p}\right)$, where $m_{1}^{*}$ is the optimal value for the number of remanufacturing cycles when there is one production cycle. Record the value of $Z\left(m_{1}^{*}, 1, \gamma_{r}, \gamma_{p}\right), m_{1}^{*}, \gamma_{r\left(m_{1}^{*}, 1\right)}^{*}$ and $\gamma_{p\left(m_{1}^{*}, 1\right)}^{*}$.

Step 3. Repeat Steps 1 and 2 for $n=2$. Compare $Z\left(m_{1}^{*}, 1, \gamma_{r}, \gamma_{p}\right)$ and $Z\left(m_{2}^{*}, 2, \gamma_{r}, \gamma_{p}\right)$. If $Z\left(m_{1}^{*}, 1, \gamma_{r}, \gamma_{p}\right)<$ $Z\left(m_{2}^{*}, 2, \gamma_{r}, \gamma_{p}\right)$, terminate the search and $Z\left(m_{1}^{*}, 1, \gamma_{r}, \gamma_{p}\right)$ is the optimum solution. If $Z\left(m_{1}^{*}, 1, \gamma_{r}, \gamma_{p}\right)>$ $Z\left(m_{2}^{*}, 2, \gamma_{r}, \gamma_{p}\right)$, then leave the value of $Z\left(m_{1}^{*}, 1, \gamma_{r}, \gamma_{p}\right)$ and repeats the Step 1 and 2 for $n=3$.

Step 4. Terminate the search once $Z\left(m_{i-1}^{*}, i-1, \gamma_{r}, \gamma_{p}\right) \geq Z\left(m_{i}^{*}, i, \gamma_{r}, \gamma_{p}\right)<Z\left(m_{i+1}^{*}, i+1, \gamma_{r}, \gamma_{p}\right)$, where $i$ is the optimal value for the number of production cycles when there are $m_{i}^{*}$ remanufacturing cycles at a $\operatorname{cost} Z\left(m_{i}^{*}, i, \gamma_{r}, \gamma_{p}\right)$.

\section{NUMERICAL EXAMPLE}

This section presents a numerical example to illustrate the presented reverse logistics fuzzy inventory model. To perform the numerical analysis, we consider the values of the input parameters in appropriate units in the following manner: $D_{p}=250, D_{r}=250, S_{p}=2400, S_{r}=1400, h_{p}=5, h_{r}=5, h_{R}=2, \beta_{p}=0.8, \beta_{r}=0.8$, $c_{w}=0.8, c_{p}=16, c_{r}=14, c_{s}=0.5, c_{R}=0.8, \delta=0.5, \eta=0.5, \Delta_{11}=100, \Delta_{12}=200, \Delta_{21}=200, \Delta_{22}=400$, $\Delta_{31}=0.5, \Delta_{32}=1, \Delta_{41}=0.5, \Delta_{42}=1, \Delta_{51}=0.2, \Delta_{52}=0.5, \Delta_{61}=0.01, \Delta_{62}=0.02, \Delta_{71}=1, \Delta_{72}=2$, $\Delta_{81}=1, \Delta_{82}=2, \Delta_{91}=0.02, \Delta_{92}=0.04, \Delta_{101}=0.025, \Delta_{102}=0.05$.

Using the solution procedure provided in the former section, we obtain the optimal policy and the computational results are summarized in Table 1 . All the calculations for finding the optimal solution are performed with the help of mathematical computational software MATHEMATICA-8.0 and the behavior of the total cost function regarding $\gamma_{p}$ and $\gamma_{r}$, when $m=3, n=1$ is shown in Figure 3.

\section{Sensitivity ANALYSiS}

To study how the parameters affect the optimal solution, the sensitivity analysis is implemented concerning the changes in system parameters. The results of the sensitivity analysis are presented in Table 2. 


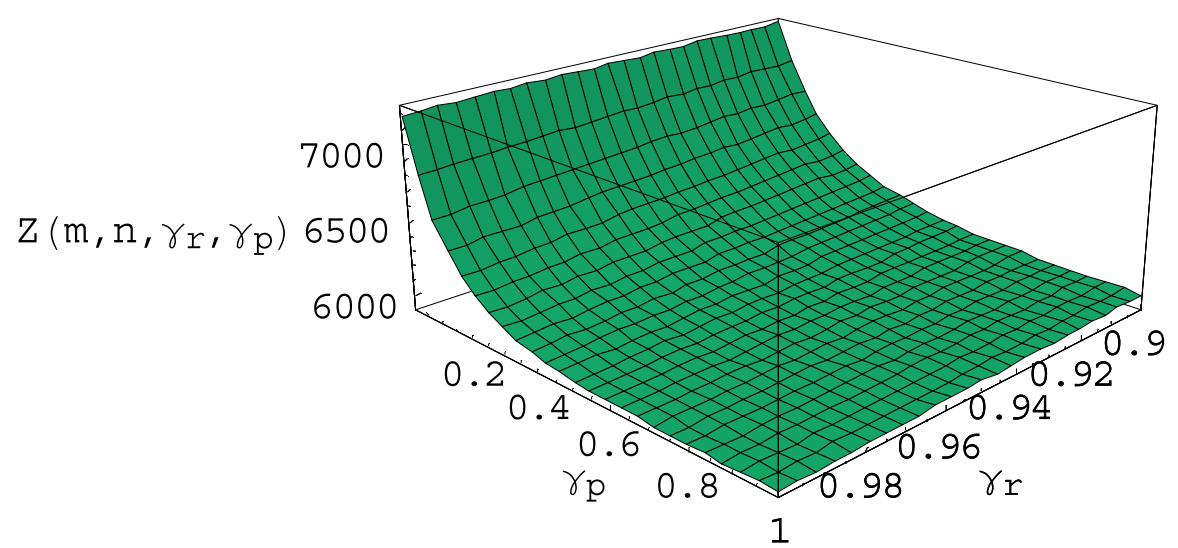

FigurE 3. Behavior of the total cost function with respect to $\gamma_{r}$ and $\gamma_{p}$ when $m=3, n=1$.

\subsection{Observations}

Some interesting findings drawn from Table 2 are summarized as follows:

(1) Table 2 shows that as per unit production cost $\left(c_{p}\right)$ decreases by $10 \%$ then the optimal solution occurs when $m=2, n=1$, and in this situation the optimal policy is to remanufacture all the collected returns from the secondary market and a proportion from the primary market. While, as $c_{p}$ decreases by $20 \%$ then the optimal solution occurs for $m=1, n=9$ and in that case, it is preferable to remanufacture minimum proportion of the collected returns from the primary market and no proportion from the secondary market. The reason is that if the production cost is small then remanufacturing is not gainful. When $c_{p}$ increases up to $20 \%$, the optimal solution takes place for $m=3, n=1$ and this suggests remanufacturing of all the collected returns from primary and secondary markets. The reason is obvious if per unit production cost is high then remanufacturing is economical than that of the production of new products. Also, it is logical that as the per unit production cost increases then obviously the total cost per unit time of the system increases. Therefore, it is economical to shrink the total production quantity to reduce the impact of increasing production cost.

(2) Table 2 reveals that as per unit holding cost of produced products $\left(h_{p}\right)$ decreases up to $20 \%$ then the optimal solution occurs for $m=3, n=1$ and the optimal policy is to remanufacture all the collected returns from the secondary market and a proportion from the primary market. While, as $h_{p}$ increases up to $20 \%$, the optimal solution takes place for $m=3, n=1$ and this recommends remanufacturing of all the collected returns from both markets. The reason is that due to higher holding cost of new products, the total cost per unit time of the system increases subsequently for decreasing the total cost it is preferable to reduce the production quantity even as remanufacture more products.

(3) Table 2 reveals that as the setup cost of the production cycle $\left(S_{p}\right)$ decreases or increases up to $20 \%$, the optimal solution exists for $m=3, n=1$ and it is advisable to remanufacture all the collected returns from the secondary market while a proportion from the primary market. Furthermore, the total cost of the system increases as $S_{p}$ increases, the reason is obvious. To reduce the negative effect on the total cost due to increasing $S_{p}$ more products should be produced during the production cycle.

(4) From Table 2, it is clear that as the production factor $(\eta)$ decreases or increases up to $20 \%$ then optimal policy exists when $m=3, n=1$ and it suggests remanufacturing all the collected returns from the secondary market. While as, it is preferable to remanufacture all the collected returns from the primary market when $\eta$ decreases and on the other hand when $\eta$ increases a proportion of the collected returns from the primary market should be remanufactured. Moreover, an increase in $\eta$ decreases the production rate, consequently, 
TABLE 2. The optimal policies for changing values of key system parameters.

\begin{tabular}{|c|c|c|c|c|c|c|c|c|}
\hline Parameter & $\%$ Change & $m$ & $n$ & $\gamma_{r}$ & $\gamma_{p}$ & $Q_{r}$ & $Q_{p}$ & $Z\left(m, n, \gamma_{r}, \gamma_{p}\right)$ \\
\hline \multirow[t]{4}{*}{$c_{p}$} & -20 & 1 & 9 & 0 & 0.010000 & 49.911 & 6238.870 & 5433.73 \\
\hline & -10 & 2 & 1 & 1 & 0.402377 & 838.378 & 520.891 & 5821.92 \\
\hline & +10 & 3 & 1 & 1 & 1.000000 & 1337.760 & 334.440 & 6015.57 \\
\hline & +20 & 3 & 1 & 1 & 1.000000 & 1337.760 & 334.440 & 6095.57 \\
\hline \multirow[t]{4}{*}{$h_{p}$} & -20 & 3 & 1 & 1 & 0.705214 & 1271.710 & 450.825 & 5910.80 \\
\hline & -10 & 3 & 1 & 1 & 0.805011 & 1296.500 & 402.633 & 5924.06 \\
\hline & +10 & 3 & 1 & 1 & 1.000000 & 1332.230 & 333.058 & 5943.92 \\
\hline & +20 & 3 & 1 & 1 & 1.000000 & 1326.770 & 331.693 & 5952.23 \\
\hline \multirow[t]{4}{*}{$S_{p}$} & -20 & 3 & 1 & 1 & 0.927357 & 1273.960 & 343.438 & 5862.12 \\
\hline & -10 & 3 & 1 & 1 & 0.915629 & 1295.470 & 353.710 & 5898.85 \\
\hline & +10 & 3 & 1 & 1 & 0.894672 & 1337.290 & 373.681 & 5970.28 \\
\hline & +20 & 3 & 1 & 1 & 0.885263 & 1357.640 & 383.401 & 6005.04 \\
\hline \multirow[t]{4}{*}{$\eta$} & -20 & 3 & 1 & 1 & 1.000000 & 1326.500 & 331.625 & 5952.64 \\
\hline & -10 & 3 & 1 & 1 & 1.000000 & 1332.100 & 333.024 & 5944.12 \\
\hline & +10 & 3 & 1 & 1 & 0.802517 & 1295.940 & 403.711 & 5923.76 \\
\hline & +20 & 3 & 1 & 1 & 0.700225 & 1270.320 & 453.540 & 5910.05 \\
\hline \multirow[t]{4}{*}{$c_{r}$} & -20 & 3 & 1 & 1 & 1.000000 & 1337.760 & 334.440 & 5375.57 \\
\hline & -10 & 3 & 1 & 1 & 1.000000 & 1337.760 & 334.440 & 5655.57 \\
\hline & +10 & 2 & 1 & 1 & 0.421850 & 852.623 & 632.653 & 6190.81 \\
\hline & +20 & 1 & 9 & 0 & 0.010000 & 49.911 & 6238.870 & 6232.85 \\
\hline \multirow[t]{4}{*}{$h_{r}$} & -20 & 3 & 1 & 1 & 1.000000 & 1401.360 & 350.339 & 5844.32 \\
\hline & -10 & 3 & 1 & 1 & 1.000000 & 1368.450 & 342.113 & 5890.47 \\
\hline & +10 & 3 & 1 & 1 & 0.811213 & 1264.840 & 389.799 & 5976.50 \\
\hline & +20 & 3 & 1 & 1 & 0.735075 & 1217.330 & 414.015 & 6015.55 \\
\hline \multirow[t]{4}{*}{$\beta_{r}$} & -20 & 2 & 1 & 1 & 1.000000 & 892.428 & 401.593 & 5991.63 \\
\hline & -10 & 2 & 1 & 1 & 0.832618 & 924.345 & 388.558 & 5974.70 \\
\hline & +10 & 4 & 1 & 1 & 0.758306 & 1752.660 & 346.693 & 5871.90 \\
\hline & +20 & 7 & 1 & 1 & 0.489152 & 3092.090 & 316.066 & 5743.46 \\
\hline \multirow[t]{4}{*}{$S_{r}$} & -20 & 3 & 1 & 1 & 0.946829 & 1240.880 & 327.640 & 5805.62 \\
\hline & -10 & 3 & 1 & 1 & 0.924341 & 1279.380 & 346.024 & 5871.37 \\
\hline & +10 & 3 & 1 & 1 & 0.887555 & 1352.590 & 380.987 & 5996.41 \\
\hline & +20 & 3 & 1 & 1 & 0.872279 & 1387.530 & 397.674 & 6056.09 \\
\hline \multirow[t]{4}{*}{$\delta$} & -20 & 3 & 1 & 1 & 0.734207 & 1195.290 & 407.001 & 6053.05 \\
\hline & -10 & 3 & 1 & 1 & 0.811688 & 1253.140 & 385.969 & 5995.70 \\
\hline & +10 & 3 & 1 & 1 & 1.000000 & 1382.640 & 345.661 & 5870.30 \\
\hline & +20 & 3 & 1 & 1 & 1.000000 & 1432.370 & 358.092 & 5802.76 \\
\hline
\end{tabular}

a lesser quantity of newly produced products have to carry in stock. Therefore, the total cost decreases, which is according to the real situation.

(5) From Table 2, it is observed that as per unit remanufacturing cost $\left(c_{r}\right)$ decreases up to $20 \%$ then the optimal solution occurs when $m=3, n=1$, then optimal policy is to remanufacture all the collected returns from both markets. The reason is that if the remanufacturing cost is small then more remanufacturing is inexpensive. When $c_{r}$ increases up to $10 \%$, the optimal solution exists for $m=2, n=1$ and this suggests remanufacturing of all the collected returns from the secondary market and partially from the primary market. While as $c_{r}$ increases by $20 \%$, the optimal solution takes place for $m=1, n=9$ and this recommends to remanufacture minimum proportion of the collected returns from the primary market and no proportion from the secondary market. The motivation is that high remanufacturing cost results 
in a highly expensive arrangement for remanufacturing and total cost increases, so remanufacturing is not preferable for this situation.

(6) Table 2 shows that as the per unit holding cost of remanufactured products $\left(h_{r}\right)$ decreases up to $20 \%$ then the optimal solution occurs when $m=3, n=1$ and remanufacturing of all the collected returns from both markets is better for this situation. While, as $h_{r}$ increases up to $20 \%$, the optimal solution occurs for $m=3$, $n=1$, and this recommends to remanufacture all the collected returns from the secondary market and a proportion from the primary market. Besides, the total cost per unit time increases as $h_{r}$ increases. It is a well-known fact that increasing holding cost obviously increases the total cost, hence to reduce the total cost it is economical to decrease the total remanufacturing quantity.

(7) Table 2 shows that as the returns fraction $\left(\beta_{r}\right)$ from the secondary market decreases up to $20 \%$ then the optimal solution occurs when $m=2, n=1$, and in this situation the optimal policy is to remanufacture almost all the collected returns from both markets. While as $\beta_{r}$ increases up to $20 \%$, the optimal solution occurs for $n=1$, and $m$ increases up to 7 , this suggests remanufacturing of all the collected returns from the secondary market and a proportion from the primary market. The reason is that if an additional fraction of used products (from secondary market) exists then additional remanufacturing and several remanufacturing cycles are reasonable because then the total cost of the system decreases.

(8) It is observed from Table 2, as the setup cost of the remanufacturing cycle $\left(S_{r}\right)$ decreases or increases up to $20 \%$, the optimal solution exists for $m=3, n=1$, and it is economical to remanufacture all the collected returns from the secondary market while as a proportion from primary market. Moreover, the total cost of the system increases as $S_{r}$ increases, the reason is that increasing cost factors harm the total cost. Therefore, to reduce the negative effect on the total cost due to increasing $S_{r}$ more products should be remanufactured during the remanufacturing cycle.

(9) From Table 2, it is clear that as the remanufacturing factor $(\delta)$ decreases or increases up to $20 \%$ then optimal policy exists when $m=3, n=1$, and it suggests remanufacturing of all the collected returns from the secondary market. While, it is economical to remanufacture a proportion of the collected returns from the primary market when $\delta$ decreases up to $20 \%$. In contrast, when $\delta$ increases up to $20 \%$ remanufacturing of all the collected returns from the primary market is inexpensive. Also, an increase in $\delta$, decreases the remanufacturing rate, as a result, a lesser quantity of remanufactured products have to carry in stock accordingly the total cost decreases.

\section{Conclusion}

In this study, we have established a reverse logistics inventory model in which the production and remanufacturing rates are finite and demand dependent. Different cost components of the model such as holding costs, setup costs, waste disposal cost, screening cost, buyback cost, production cost, and remanufacturing cost are taken as the triangular fuzzy numbers. The total cost per unit time of the developed reverse logistics inventory system is defuzzified with the signed distance method. Then, the corresponding optimal production and remanufacturing policy is derived to minimize the total cost. The presented paper is illustrated with a numerical example. The u-shaped behavior of the total cost function is made available graphically. The major outcome from the sensitivity analysis is that in almost all situations the remanufacturing is gainful, except only when the production cost is very low and the remanufacturing cost is too much high. Thus, with these realistic attributes, the presented model is much closer to the realistic situations and supportive for the decision-makers in planning and controlling production and remanufacturing business. This model can be further extended by considering the supply chain of two or more members. Also, it would be interesting to investigate the impact of carbon emission, inflation, and deterioration in future research. Furthermore, some other interesting directions for future works are to incorporate shortages, permissible delay in payment, and variable demand rates. 


\section{Appendix A.}

During the time period $T$ there are $m$ remanufacturing cycles each of length $T_{R}$ and $n$ production/manufacturing cycles each of length $T_{P}$. Therefore, we have

$$
m T_{R}+n T_{P}=T, m \geq 1, n \geq 1 .
$$

Since, the total demand of the remanufactured products during $m$ remanufacturing cycles is fulfilled by remanufacturing the total accumulated repairable used products, so

$$
D_{r}\left(m T_{R}\right)=\left[\gamma_{r} \beta_{r} D_{r}\left(m T_{R}\right)+\gamma_{p} \beta_{p} D_{p}\left(n T_{p}\right)\right] \Rightarrow T_{P}=\frac{m}{n}\left(\frac{\left(1-\gamma_{r} \beta_{r}\right)}{\gamma_{p} \beta_{p}}\right) \frac{D_{r} T_{R}}{D_{p}} .
$$

Substituting the value of $T_{P}$ from equation (A.2) in equation (A.1) and then simplifying, we get

$$
T_{R}=\frac{\gamma_{p} \beta_{p} D_{p} T}{m g}, \text { where } g=\left(D_{r}+\gamma_{p} \beta_{p} D_{p}-\gamma_{r} \beta_{r} D_{r}\right) \text { (say) }
$$

Now, substituting the value of $T_{R}$ from equation (A.3) in equation (A.2), we get

$$
T_{P}=\frac{\left(1-\gamma_{r} \beta_{r}\right) D_{r} T}{n g}
$$

Now total remanufacturing quantity during $m$ cycles $\left(Q_{r}\right)$ is

$$
Q_{r}=\left[\frac{D_{r}}{\delta}\left(\delta T_{R}\right)\right] m=D_{r} m T_{R} .
$$

Total production quantity during $n$ cycles $\left(Q_{p}\right)$ is

$$
Q_{p}=\left[\frac{D_{p}}{\eta}\left(\eta T_{P}\right)\right] n=D_{p} n T_{P}
$$

Total purchasing quantity of used products $\left(Q_{R}\right)$ is

$$
Q_{R}=\left[\left(\beta_{r} D_{r}\right) m T_{R}+\left(\beta_{p} D_{p}\right) n T_{P}\right] .
$$

The total cost per unit time for the presented production and remanufacturing inventory system consists of the following cost components:

(a) The set up cost per unit time (SC) for the system is

$$
\mathrm{SC}=\frac{\left(m S_{r}+n S_{p}\right)}{T}
$$

(b) The total inventory holding cost per unit time $\left(\mathrm{HC}_{T}\right)$ is $\mathrm{HC}_{T}=\frac{\mathrm{HC}_{p}+\mathrm{HC}_{r}+\mathrm{HC}_{R}}{T}$ (see Appendices $\mathrm{B}$ and $\mathrm{C}$ for $\mathrm{HC}_{p} \mathrm{HC}_{r}$ and $\mathrm{HC}_{R}$ ).

$$
\begin{aligned}
= & \frac{D_{r} D_{p} T}{2 g^{2}}\left[\frac{h_{p}(1-\eta)\left(1-\gamma_{r} \beta_{r}\right)^{2} D_{r}}{n}+\frac{h_{r}(1-\delta) \gamma_{p}^{2} \beta_{p}^{2} D_{p}}{m}+\frac{h_{R} \gamma_{p}^{2} \beta_{p}^{2} D_{p}}{m}\right. \\
& \times\left\{\left(1-\delta \gamma_{r} \beta_{r}\right) \delta+\gamma_{r} \beta_{r}(1-\delta)^{2}+\frac{m\left(1-\gamma_{r} \beta_{r}\right)^{2} D_{r}}{\gamma_{p} \beta_{p} D_{p}}+\left(1-\gamma_{r} \beta_{r}\right)(m-1)\right. \\
& \left.\left.+\frac{2 \gamma_{r} \beta_{r} D_{r}(1-\delta)\left(1-\gamma_{r} \beta_{r}\right)}{\gamma_{p} \beta_{p} D_{p}}\right\}\right]
\end{aligned}
$$


or

$$
\mathrm{HC}_{T}=T \phi\left(m, n, \gamma_{r}, \gamma_{p}\right)
$$

where,

$$
\begin{aligned}
\phi\left(m, n, \gamma_{r}, \gamma_{p}\right)= & \frac{D_{r} D_{p}}{2 g^{2}}\left[\frac{h_{p}(1-\eta)\left(1-\gamma_{r} \beta_{r}\right)^{2} D_{r}}{n}+\frac{h_{r}(1-\delta) \gamma_{p}^{2} \beta_{p}^{2} D_{p}}{m}\right. \\
& +\frac{h_{R} \gamma_{p}^{2} \beta_{p}^{2} D_{p}}{m}\left\{\left(1-\delta \gamma_{r} \beta_{r}\right) \delta+\gamma_{r} \beta_{r}(1-\delta)^{2}+\frac{m\left(1-\gamma_{r} \beta_{r}\right)^{2} D_{r}}{\gamma_{p} \beta_{p} D_{p}}\right. \\
& \left.\left.+\left(1-\gamma_{r} \beta_{r}\right)(m-1)+\frac{2 \gamma_{r} \beta_{r} D_{r}(1-\delta)\left(1-\gamma_{r} \beta_{r}\right)}{\gamma_{p} \beta_{p} D_{p}}\right\}\right]
\end{aligned}
$$

(c) The disposal cost per unit time (DC) for the system is

$$
\mathrm{DC}=\frac{c_{w}}{T}\left[\left(1-\gamma_{p}\right) \beta_{p} D_{p} n T_{P}+\left(1-\gamma_{r}\right) \beta_{r} D_{r} m T_{R}\right]
$$

(d) The remanufacturing cost per unit time (RC) is

$$
\mathrm{RC}=\frac{c_{r} Q_{r}}{T} .
$$

(e) The production cost per unit time (PC) is

$$
\mathrm{PC}=\frac{c_{p} Q_{p}}{T} .
$$

(f) The purchasing cost per unit time (PUC) for used products is

$$
\mathrm{PUC}=\frac{c_{R} Q_{R}}{T} .
$$

(g) The screening cost per unit time (SN) for collected used products is

$$
\mathrm{SN}=\frac{c_{s} Q_{R}}{T} .
$$

So, the total cost per unit time of the proposed inventory system $\left(C\left(m, n, \gamma_{r}, \gamma_{p}, T\right)\right)$ is

$$
\begin{aligned}
C\left(m, n, \gamma_{r}, \gamma_{p}, T\right)= & {\left[\mathrm{SC}+\mathrm{HC}_{T}+\mathrm{DC}+\mathrm{RC}+\mathrm{PC}+\mathrm{PUC}+\mathrm{SN}\right] } \\
= & {\left[\frac{\left(m S_{r}+n S_{p}\right)}{T}+T \phi\left(m, n, \gamma_{r}, \gamma_{p}\right)+\frac{c_{w}}{T}\left\{\left(1-\gamma_{p}\right) \beta_{p} D_{p} n T_{P}\right.\right.} \\
& \left.\left.+\left(1-\gamma_{r}\right) \beta_{r} D_{r} m T_{R}\right\}+\frac{c_{r} Q_{r}}{T}+\frac{c_{p} Q_{p}}{T}+\frac{c_{R} Q_{R}}{T}+\frac{c_{s} Q_{R}}{T}\right] .
\end{aligned}
$$

Substituting, the values of $T_{R}, T_{P}, Q_{r}, Q_{p}$, and $Q_{R}$ from the equations (A.3), (A.4), (A.5), (A.6) and (A.7), respectively and then simplifying, we get

$$
\begin{aligned}
C\left(m, n, \gamma_{r}, \gamma_{p}, T\right)= & {\left[\frac{\left(m S_{r}+n S_{p}\right)}{T}+T \phi\left(m, n, \gamma_{r}, \gamma_{p}\right)+\frac{D_{r} D_{p}}{g}\left\{c_{w} \beta_{p}\left(1-\gamma_{p}+\beta_{r}\left(\gamma_{p}-\gamma_{r}\right)\right)\right.\right.} \\
& \left.\left.+c_{r} \gamma_{p} \beta_{p}+c_{p}\left(1-\gamma_{r} \beta_{r}\right)+\left(c_{R}+c_{s}\right) \beta_{p}\left(1-\gamma_{r} \beta_{r}+\gamma_{p} \beta_{r}\right)\right\}\right]
\end{aligned}
$$




\section{Appendix B.}

Holding cost for newly produced products (see Figure 2) during $n$ production cycles is $\mathrm{HC}_{p}=$ $h_{p} . n$. (the area of the triangle I + the area of the triangle II).

$$
\mathrm{HC}_{p}=h_{p} n\left[\frac{1}{2}\left(\left(\frac{D_{p}}{\eta}-D_{p}\right) \eta T_{P}\right) \eta T_{P}+\frac{1}{2}\left(D_{p}(1-\eta) T_{P}\right)(1-\eta) T_{P}\right]=\frac{h_{p} n(1-\eta) D_{p} T_{P}^{2}}{2}
$$

Substituting the value of $T_{P}$ from (A.4) and then solving, we get

$$
\mathrm{HC}_{p}=\frac{h_{p}(1-\eta) D_{p}\left(1-\gamma_{r} \beta_{r}\right)^{2} D_{r}^{2} T^{2}}{2 n g^{2}} .
$$

Holding cost for remanufactured products (see Figure 2) during $m$ remanufacturing cycles is $\mathrm{HC}_{r}=$ $h_{r} . m$. (the area of the triangle $1+$ the area of the triangle 2 ).

$$
\mathrm{HC}_{r}=h_{r} m\left[\frac{1}{2}\left(\left(\frac{D_{r}}{\delta}-D_{r}\right) \delta T_{R}\right) \delta T_{R}+\frac{1}{2}\left(D_{r}(1-\delta) T_{R}\right)(1-\delta) T_{R}\right]=\frac{h_{r} m(1-\delta) D_{r} T_{R}^{2}}{2} .
$$

Substituting the value of $T_{R}$ from (A.3) and then solving, we get

$$
\mathrm{HC}_{r}=\frac{h_{r}(1-\delta) D_{r} \gamma_{p}^{2} \beta_{p}^{2} D_{p}^{2} T^{2}}{2 m g^{2}}
$$

\section{Appendix C.}

According to the Figure C.1 we calculate the holding cost for repairable used products as follows:

Area of part $A$ is

$$
\Delta_{A}=\left(\frac{1}{2}\left(\frac{D_{r}}{\delta}-\gamma_{r} \beta_{r} D_{r}\right) \delta T_{R}\right) \delta T_{R}=\frac{1}{2}\left(1-\delta \gamma_{r} \beta_{r}\right) \delta D_{r} T_{R}^{2}
$$

Area of part $B$ is

$$
\Delta_{B}=\left(\frac{1}{2} \gamma_{r} \beta_{r} D_{r}(1-\delta) T_{R}\right)(1-\delta) T_{R}=\frac{1}{2} \gamma_{r} \beta_{r} D_{r}(1-\delta)^{2} T_{R}^{2} .
$$

Area of part $C$ is

$$
\Delta_{C}=\left(\frac{1}{2} \gamma_{p} \beta_{p} D_{p} n T_{P}\right) n T_{P}=\frac{1}{2} \gamma_{p} \beta_{p} D_{p} n^{2} T_{P}^{2}
$$

Area of part $D$ is

$$
\Delta_{D}=\left(\gamma_{r} \beta_{r} D_{r}(1-\delta) T_{R}\right) n T_{P}=\gamma_{r} \beta_{r} D_{r}(1-\delta) n T_{R} T_{P}
$$

Area of part $E_{i}$ is

$$
\Delta_{E_{i}}=\left(\left(\frac{D_{r}}{\delta}-\gamma_{r} \beta_{r} D_{r}\right) \delta T_{R}-\gamma_{r} \beta_{r} D_{r}(1-\delta) T_{R}\right) i T_{R}=\left(1-\gamma_{r} \beta_{r}\right) i D_{r} T_{R}^{2} .
$$

Therefore, holding cost for repairable used products is

$$
\mathrm{HC}_{R}=h_{R}\left[m \Delta_{A}+m \Delta_{B}+\Delta_{C}+\Delta_{D}+\sum_{i=1}^{m-1} \Delta_{E_{i}}\right] .
$$

After substituting all values and then solving we get

$$
\begin{aligned}
\mathrm{HC}_{R}= & \frac{h_{R} \gamma_{p}^{2} \beta_{p}^{2} D_{p}^{2} D_{r} T^{2}}{2 m g^{2}}\left\{\left(1-\delta \gamma_{r} \beta_{r}\right) \delta+\gamma_{r} \beta_{r}(1-\delta)^{2}+\frac{m\left(1-\gamma_{r} \beta_{r}\right)^{2} D_{r}}{\gamma_{p} \beta_{p} D_{p}}\right. \\
& \left.+\frac{2 \gamma_{r} \beta_{r} D_{r}(1-\delta)\left(1-\gamma_{r} \beta_{r}\right)}{\gamma_{p} \beta_{p} D_{p}}+\left(1-\gamma_{r} \beta_{r}\right)(m-1)\right\} .
\end{aligned}
$$


Repairable Stock

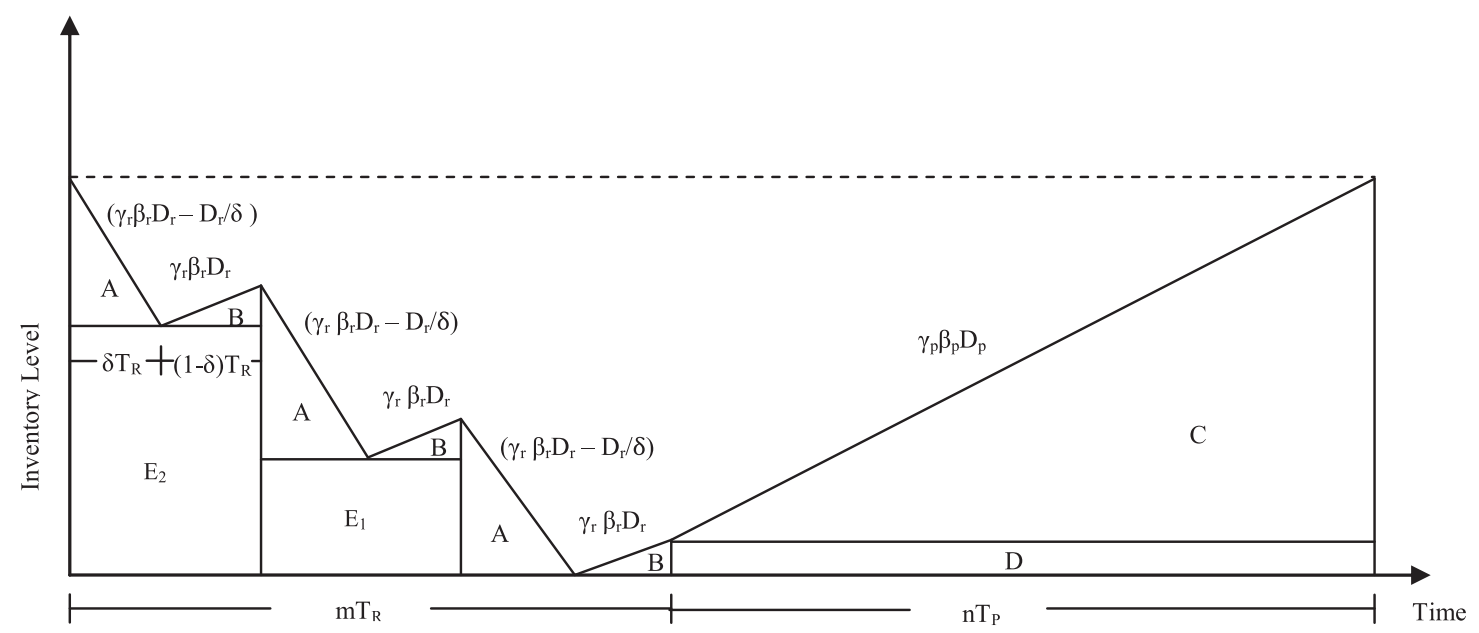

Figure C.1. Inventory estimation for $\mathrm{HC}_{R}$.

\section{REFERENCES}

[1] A.A. Alamri, Theory and methodology on the global optimal solution to a general reverse logistics inventory model for deteriorating items and time-varying rates. Comput. Ind. Eng. 60 (2011) 236-247.

[2] E. Bazan, M.Y. Jaber and S. Zanoni, A review of mathematical inventory models for reverse logistics and the future of its modeling: An environmental perspective. Appl. Math. Model. 40 (2016) 4151-4178.

[3] J.D. Blackburn, V.D.R. Guide, G.C. Souza and L.N. Van Wassenhove, Reverse supply chains for commercial returns. California Manage. Rev. 46 (2004) 6-22.

[4] H.C. Chang, An application of fuzzy sets theory to the EOQ model with imperfect quality items. Comput. Oper. Res. 31 (2004) 2079-2092.

[5] S.C. Chang, Fuzzy production inventory for fuzzy product quantity with triangular fuzzy number. Fuzzy Sets Syst. 107 (1999) $37-57$.

[6] L.H. Chen and L.H. Ouyang, Fuzzy inventory model for deteriorating items with permissible delay in payment. Appl. Math. Comput. 182 (2006) 711-726.

[7] W. Chen, L. Wei and Y. Li, Fuzzy multicycle manufacturing/remanufacturing production decisions considering inflation and the time value of money. J. Cleaner Prod. 198 (2018) 1494-1502.

[8] I. Dobos and K. Richter, A production/recycling model with stationary demand and return rates. Central Eur. J. Oper. Res. 11 (2003) 35-46.

[9] I. Dobos and K. Richter, An extended production/recycling model with stationary demand and return rates. Int. J. Prod. Econ. 90 (2004) 311-323.

[10] D. Dubois and H. Prade, Fuzzy Sets and Systems: Theory and Applications. Academic Press, New York (1980).

[11] A.M.A. El Saadany and M.Y. Jaber, A production/remanufacturing inventory model with price and quality dependant return rate. Comput. Ind. Eng. 58 (2010) 352-362.

[12] T. Garai, D. Chakraborty and T.P. Roy, Fully fuzzy inventory model with price-dependent demand and time varying holding cost under fuzzy decision variables. J. Intell. Fuzzy Syst. 36 (2019) 3725-3738.

[13] K.A. Halim, B.C. Giri and K.S. Chaudhuri, Fuzzy production planning models for an unreliable production system with fuzzy production rate and stochastic/fuzzy demand rate. Int. J. Ind. Eng. Comput. 2 (2011) 179-192.

[14] P. Hasanov, M.Y. Jaber and S. Zolfaghari, Production remanufacturing and waste disposal model for a case of the cases of pure and partial backordering. Appl. Math. Modell. 36 (2012) 5249-5261.

[15] P. Hasanov, M.Y. Jaber and N. Tahirov, Four-level closed loop supply chain with remanufacturing. Appl. Math. Modell. 66 (2019) 141-155.

[16] M.Y. Jaber and A.M.A. El Saadany, The production, remanufacture and waste disposal model with lost sales. Int. J. Prod. Econ. 120 (2009) 115-124.

[17] A. Kaufmann and M.M. Gupta, Introduction to Fuzzy Arithmetic Theory and Applications. Van Nostrand Reinhold, New York (1991).

[18] M. Kumar, A novel weakest $t$-norm based fuzzy fault tree analysis through qualitative data processing and its application in system reliability evaluation. J. Intell. Syst. 29 (2018) 977-993. 
[19] M. Kumar, A novel weakest $t$-norm based fuzzy importance measure for fuzzy fault tree analysis of combustion engineering reactor protection system. Int. J. Uncertainty Fuzziness Knowl.-Based Syst. 27 (2019) 949-967.

[20] M. Kumar, Measuring Pearson's correlation coefficient of fuzzy numbers with different membership functions under weakest t-norm. Int. J. Data Anal. Tech. Strategies 12 (2020) 172-186.

[21] N. Nahmias and H. Rivera, A deterministic model for a repairable item inventory system with a finite repair rate. Int. J. Prod. Res. 17 (1979) 215-221.

[22] S. Pal, G.S. Mahapatra and G.P. Samanta, An EPQ model of ramp type demand with Weibull deterioration under inflation and finite horizon in crisp and fuzzy environment. Int. J. Prod. Econ. 156 (2014) 159-166.

[23] V. Polotski, J.-P. Kenne and A. Gharbi, Production and setup policy optimization for hybrid manufacturing-remanufacturing systems. Int. J. Prod. Econ. 183 (2017) 322-333.

[24] K. Richter, The EOQ repair and waste disposal model with variable setup numbers. Eur. J. Oper. Res. 95 (1996) $313-324$.

[25] K. Richter, The extended EOQ repair and waste disposal model. Int. J. Prod. Econ. 45 (1996) 443-447.

[26] D.A. Schrady, A deterministic inventory model for repairable items. Nav. Res. Logistics Q. 14 (1967) $391-398$.

[27] C. Singh and S.R. Singh, Progressive trade credit policy in a supply chain with and without stock-out for supplier's lead time under inflationary and fuzzy environment. Syst. Sci. Control Eng. 3 (2015) 284-299.

[28] S.R. Singh and S. Sharma, A production reliable model for deteriorating products with random demand and inflation. Int. J. Syst. Sci. Oper. Logistics 4 (2017) 330-338.

[29] S.R. Singh and S. Sharma, A partially backlogged supply chain model for deteriorating items under reverse logistics, imperfect production/remanufacturing and inflation. Int. J. Logistics Syst. Manage. 33 (2019) 221-255.

[30] S.R. Singh, S. Sharma and M. Kumar, Inventory models with multiple production and remanufacturing batches under shortages. Control Cybern. 45 (2016) 385-416.

[31] S.R. Singh, S. Sharma and M. Kumar, A reverse logistics model for decaying items with variable production and remanufacturing incorporating learning effects. Int. J. Oper. Res. 38 (2020) 422-448.

[32] M. Vujošević, D. Petrović and R. Petrović, EOQ formula when inventory cost is fuzzy. Int. J. Prod. Econ. 45 (1996) $499-504$.

[33] D. Yadav, S.R. Singh and R. Kumari, Inventory model with learning effect and imprecise market demand under screening error. Opsearch 50 (2013) 418-432.

[34] J.S. Yao, S.C. Chang and J.S. Su, Fuzzy inventory without backorder for fuzzy order quantity and fuzzy total demand quantity. Comput. Oper. Res. 27 (2000) 935-962.

[35] L.A. Zadeh, Fuzzy sets. Inf. Control 8 (1965) 338-353.

[36] H.J. Zimmermann, Fuzzy Set Theory and its Applications, 3rd edition. Kluwer Academic Publishers, Dordrecht (1996). 